\title{
Prevalence and determinants of cardiovascular disease risk factors among the residents of urban community housing projects in Malaysia
}

\author{
Mohammadreza Amiri', Hazreen Abdul Majid², FarizahMohd Hairi ${ }^{2}$, Nithiah Thangiah², Awang Bulgiba ${ }^{3}$, \\ $\operatorname{Tin} \operatorname{Tin} \mathrm{Su}^{2^{*}}$
}

From International Research Symposium on Population Health 2013

Kuala Lumpur, Malaysia. 18-22 November 2013

\begin{abstract}
Objectives: The objectives are to assess the prevalence and determinants of cardiovascular disease (CVD) risk factors among the residents of Community Housing Projects in metropolitan Kuala Lumpur, Malaysia.

Method: By using simple random sampling, we selected and surveyed 833 households which comprised of 3,722 individuals. Out of the 2,360 adults, 50.5\% participated in blood sampling and anthropometric measurement sessions. Uni and bivariate data analysis and multivariate binary logistic regression were applied to identify demographic and socioeconomic determinants of the existence of having at least one CVD risk factor.
\end{abstract}

Results: As a Result, while obesity (54.8\%), hypercholesterolemia (51.5\%), and hypertension (39.3\%) were the most common CVD risk factors among the low-income respondents, smoking (16.3\%), diabetes mellitus (7.8\%) and alcohol consumption (1.4\%) were the least prevalent. Finally, the results from the multivariate binary logistic model illustrated that compared to the Malays, the Indians were $41 \%$ less likely to have at least one of the CVD risk factors (OR $=0.59 ; 95 \% \mathrm{Cl}: 0.37-0.93)$.

Conclusion: In Conclusion, the low-income individuals were at higher risk of developing CVDs. Prospective policies addressing preventive actions and increased awareness focusing on low-income communities are highly recommended and to consider age, gender, ethnic backgrounds, and occupation classes.

\section{Background}

While declining trends in mortality due to CVD have been observed in developed nations in the recent decades, there has been a dramatic rise in low and middle-income countries instead [1,2]. As the transition towards developed economies raise living standards, it may jeopardize the health of lower socioeconomic groups. In addition, economic growth and urbanization are associated with higher prevalence of chronic non-communicable diseases (NCD) in developing countries [3]. Hence, population in

\footnotetext{
* Correspondence: tintinsu03@yahoo.com

${ }^{2}$ Centre for Population Health (CePH), Department of Social and Preventive Medicine, Faculty of Medicine, University of Malaya, 50603, Kuala Lumpur, Malaysia

Full list of author information is available at the end of the article
}

developing nations is at a higher risk of getting CVDs [4-6].

Malaysia is classified as a developing country [7]. It is a multi-ethnic nation with a growing population[8] experiencing rapid urbanization and vast changes in lifestyles, including poorer dietary habits and less physical activities [9]. Chronic illnesses in Malaysia are due to both demographic and socioeconomic transitions caused by economic development [10] which will result in higher prevalence of NCDs in Malaysia [11]. Mortality due to CVDs in Malaysian hospitals has risen dramatically from $15.7 \%$ in 1996 to $25.4 \%$ in $2006[12,13]$ and is expected to increase in the subsequent decades $[14,15]$.

Malaysia consists of different ethnic and socioeconomic groups $[8,16]$. It is proven that socioeconomic status (SES) influences the health condition [17-19]. In addition, higher 
socioeconomic inequalities [20] and lower levels of income [21], education [22,23], and occupational status [2,24] are highly associated with the risk of CVDs. Furthermore, living in urban areas increases the risk of CVDs [25] as the health expenditures are higher, socioeconomic inequalities are wider, and the living environment is worse compared to rural areas. Finally, besides environmental transition, urban transition also influences the living lifestyle, including living costs, higher stress level, dietary habits, physical activities, and smoking habits, which are more damaging to the health condition [26].

In this study, we aimed at identifying the prevalence and determinants of the most established CVD risk factors (i.e. hypertension, hypercholesterolemia, smoking, overweight and/or obesity [27-29] and diabetes mellitus [30,31]) among the residents of urban Community Housing Projects [i.e. in local language: PPR (Projek Perumahan Rakyat)] located in the metropolitan Kuala Lumpur, Malaysia. These Community Housing Projects are densely populated with low socioeconomic groups. This study has several advantages compared to the previous research. First, it is an unprecedented research in studying the PPR residents in Malaysian's metropolitan areas. Second, this study not only covers as many CVD risk factors as the previous nation-wide studies have done [12-15], but in fact it has more risk factors compared to them [32-35]. Finally, this study is the baseline for a-five-year longitudinal research and the findings from this study will be applied to establish tailor-made interventions for vulnerable lower socioeconomic population in metropolitan areas.

\section{Methods \\ Study setting}

The study was conducted in four Community Housing Projects [i.e. PPR Kerinchi, PPR Pantai Ria, PPR Seri Cempaka and PPR Seri Pantai] located in the Lembah Pantai area of metropolitan Kuala Lumpur, Malaysia. These PPRs were developed by Kuala Lumpur City Hall in their squatter resettlement programme. The units in the community housing projects were only allocated to families: 1.with at least one child; 2.with household's monthly income below MYR 2,000 (MYR: Malaysian Ringgit); and, 3.who does not own any property within $35 \mathrm{~km}$ from Kuala Lumpur. These requirements were applied in the early 2000 when the resettlement programme was established.

\section{Data collection and sample size}

Sample size was determined by Stata software v11.2 (StataCorp LP, TX, USA). For the population, we used standardised population of Malaysia who live in the urban areas (i.e. about 20 million individuals, which is $72 \%$ of the total population of Malaysia)[8]. Based on recent national survey [14], we used the highest CVD risk factors frequency in Malaysia [i.e. hypercholesterolemia (35.1\%)]. We assumed the true frequencies of the surveyed population to lie between \pm 5 percent confidence limits, the power to be $80 \%$, and the confidence interval to be $95 \%$. The calculated sample size was 350 . However, we decided to include all eligible participants from the household survey conducted in Lembah Pantai area to increase the precision of the analysis.

This survey was a cross-sectional design and conducted between February to November 2012. Altogether, 833 households were recruited from the total of 4726 households from four Community Housing Projects by using simple random sampling method.

The members of the selected households were administered questionnaire survey in either Bahasa Malaysia or English. Then, the respondents aged eighteen years and above, were invited to the predefined medical centers for blood sampling and anthropometrical measurements. All evaluations were conducted by professional teams led by a medical doctor. Written consents were taken from all respondents.

\section{Measurement}

Anthropometric measurements included height (measured by SECA 217 Stadiometer for Mobile Height Measurement and rounded to the nearest one $\mathrm{mm}$ ), weight (measured by SECA 813 Digital High Capacity Floor Scale and rounded to the nearest $0.1 \mathrm{~kg}$ ), and waist and hip circumference (measured by SECA 201Ergonomic circumference measuring tape in $\mathrm{cm}$ ). The arterial blood pressure (measured by Omron HEM7211 Automatic Blood Pressure Monitor), and non-fasting random blood sugar and lipid profile were also assessed (by Dimension Vista ${ }^{\circledR}$ 1500 Intelligent Lab). The lab investigations were done in a certified laboratory of a tertiary hospital.

\section{Study variables}

\section{Cardiovascular disease risk factors}

The CVD risk factors were classified as follows $[27,36]$ : the elevated blood pressure was considered as hypertension if Systolic and/or Diastolic Blood Pressure equaled or above140/90 $\mathrm{mm} \mathrm{Hg}$ or if any antihypertensive medications were used. To be a diabetic the Random Blood Sugar (RBS) readings were equal to or above $11.0 \mathrm{mmol} / \mathrm{L}$ and/ or were under diabetes treatment [37]. In addition, high risk of diabetes was determined if the RBS levels were between 5.6 and $11.0 \mathrm{mmol} / \mathrm{L}$. Those who had Total Cholesterol (TC) $\geq 5.2 \mathrm{mmol} / \mathrm{L}$ and/or were using cholesterol-lowering drugs were categorized as hypercholesterolemics. To qualify as overweight and obese, the Asian classifications of Body Mass Index (BMI, $\mathrm{kg} / \mathrm{m}^{2}$ ) from 23.0 to 24.9 , and over $25.0 \mathrm{~kg} / \mathrm{m}^{2}$ were used respectively $[38,39]$. However, there have been debates on 
consideration of $25 \mathrm{~kg} / \mathrm{m}^{2}$ up to $27.5 \mathrm{~kg} / \mathrm{m}^{2}$ as overweight or pre-obese for Asians [38-42], but we chose to classify $25 \mathrm{~kg} / \mathrm{m}^{2}$ and above (i.e. where public health interventions must take effect) as obesity (i.e. obesity includes high risk overweight, pre-obese and obese types I, II, and III) according to WHO Expert Consultation [38]. Smokers were adults who smoked at least a cigarette per day[43]. Drinking one sip of alcoholic beverage per day was considered as alcohol risk factor[1]. Having at least one of the above CVD risk factors was considered as the outcome of the logistic regression model.

\section{Demographic and socioeconomic characteristics}

Age classifications were 18 to 29,30 to 39,40 to 49,50 to 59 , and $60 \leq$ in the bivariate analysis. However, the logistic model was controlled for continuous values of age. Ethnically, the population distribution of Malaysia is Malays (67.4\%), Chinese (24.6\%), Indians (7.3\%), and other ethnic/race groups (0.7\%) [8]. Hence, we classified the ethnic/race variable into Malays, Indians, and Chinese or others minor ethnic groups. Finally, the marital status was categorized as single, married, widowed/widower, and divorced sub-groups[16].

The education grades were classified as none (zero years of study), primary ( $<7$ years), secondary ( $7-12$ years) and tertiary levels ( $>12$ years). For classification of income levels, the Malaysia's cut-off point of poverty line in the year 2009 (i.e. MYR786) was considered and adjusted for inflation rate and living expenses of metropolitan Kuala Lumpur [44]. Hence, after rounding up, MYR1,000 was the threshold of poverty. Therefore, the monthly household income was classified as MYR $<1,000$ (the poor) or others. Finally, the paid-employee, self-employed, retirees, homemakers, and others were the categories of occupational status.

\section{Statistical analyses}

First, descriptive data analysis was carried out. Then, individual and existence of at least the CVD risk factors were tabulated against the demographic and socioeconomic variables. The $\chi^{2}$ probabilityillustrated whether the relationships were significant or not (note: level of 0.05 was considered). Finally, binomial multivariate logistic regression assessed the demographic and socioeconomic determinants of the existence of at least one of the CVD risk factors. We followed the STROBE statement in reporting our research [45].

\section{Results and discussion \\ Descriptive analysis}

Altogether, the data from 3,722 individuals (833 households) were collected in the initial household survey in the PPRs. Then, from 2,360 respondents ( $\geq 18$ years old) who were invited to attend the medical screening and anthropometric measurements, 1,192 (50.5\%) participated. We further tested the representativeness of the selected respondents according to age distribution, gender, and ethnic/race groups and we saw no significant difference existed.

We had comprehensive data for 1,096 respondents after eliminating the missing values. The mean age of the respondents was 41.5 years (SD: 14.9). The majority of the respondents were over 30 years old $(73.8 \%)$, females (56.3\%), Malays $(82.1 \%)$, married (64.0\%), and had secondary education (65.5\%). Less than MYR1,000 per month earners were 17.5 percent of the whole sample population (see Table 1).

Obesity (54.8\%), hypercholesterolemia (51.5\%), and hypertension (39.3\%) were the most prevalent CVD risk factors. According to The Fourth National Health and Morbidity Survey of Malaysia [14], the obesity, hypercholesterolemia and hypertension risk factors in Malaysia accounted for 27.2, 35.1, and 32.7 percent respectively. Hence, comparing the figures between the low-income urban communities and at the national level, the prevalence of each CVD risk factor is much higher in the lowincome community group. For instance, the low-income adults were more than two times obese compared to the national level. Finally, the highest prevalence of at least

Table 1 Socio-demographic characteristics of the study (n = 1,096).

\begin{tabular}{llc}
\hline Variables & Sub-categories & $\mathbf{N}(\%)$ \\
\hline Age & 18 to 29 & $288(26.3)$ \\
& 30 to 39 & $213(19.4)$ \\
& 40 to 49 & $255(23.3)$ \\
& 50 to 59 & $201(18.4)$ \\
& $\geq 60$ & $139(12.7)$ \\
Gender & Male & $479(43.7)$ \\
Ethnicity & Female & $517(56.3)$ \\
& Malay & $899(82.1)$ \\
Education & Indian & $181(16.5)$ \\
& Chinese/Others & $16(1.4)$ \\
Income & None & $78(7.1)$ \\
& Primary & $186(17.0)$ \\
Occupation & Secondary & $718(65.5)$ \\
& Tertiary & $114(10.4)$ \\
& $<1,000$ RM & $192(17.5)$ \\
& $\geq 1,000$ RM & $904(82.5)$ \\
& Paid-employee & $463(42.2)$ \\
Marital status & Self-employed & $138(12.6)$ \\
& Retiree & $42(3.8)$ \\
& House maker & $237(21.6)$ \\
& Others & $216(19.7)$ \\
& Single & $277(25.3)$ \\
& Married & $701(64.0)$ \\
& Divorced & $67(6.1)$ \\
& Widow/Widower & $51(4.6)$ \\
\hline & &
\end{tabular}


one of the CVD risk factors was among 50 to 59 yearold adults, male, Chinese, and divorced (demographically), and the primary educated, less than MYR1,000 monthly income earners, and self-employed adults (socioeconomically).

Demographically, respondents in their 50's and above 60 years had the highest prevalence of hypertension (i.e. 63.7 and 73.4 percent respectively) and diabetes (i.e. 17.9 and 11.5). Hypercholesterolemia and obesity were the highest among middle-aged adults who were in their 40's (i.e. $62.4 \%$ and $64.3 \%$ respectively). Younger respondents had higher prevalence of smoking, i.e. 30's and 40's accounted for 21.1 and 19.2 percent respectively. The widowed and divorced were most hypertensive. In addition, diabetes and obesity were the most prevalent in divorced people with 13.4 and 67.2 percent respectively. Those who were married had the highest prevalence of hypercholesterolemia and smoking, i.e. 57.6 and 19.5 percent respectively. Respondents with primary education had the highest level of hypertension (58.6\%), diabetes $(11.8 \%)$, and obesity (60.2\%) whereas adults with secondary education had the highest prevalence of hypercholesterolemia and smoking by 53.8 and 17.6 percent respectively. In terms of occupational status, the highest prevalence of hypercholesterolemia, smoking, and diabetes were experienced by self-employed respondents. Finally, while the poorest respondents (i.e. $<$ MYR1,000 monthly income) were the most hypertensive (50.5\%) and being smokers $(17.2 \%)$, the other income categories had higher prevalence of other CVD risk factors.(see Table 2).

The prevalence of CVD risk factors according to gender is shown in Figure 1. For instance, comparatively men had a higher prevalence of hypercholesterolemia (54.7\%) and smoking (36.1\%), while women were more hypertensive $(39.7 \%)$, diabetic $(7.9 \%)$, and obese (59.3\%).

Table 2 Prevalence of individual CVD risk factors $(n=1,096)$.

\begin{tabular}{|c|c|c|c|c|c|c|c|c|}
\hline & \multirow[t]{2}{*}{ Hypertension } & \multirow[t]{2}{*}{ Hypercholesterolemia } & \multirow[t]{2}{*}{ Smoking } & \multicolumn{2}{|c|}{ Diabetes } & \multicolumn{2}{|c|}{ Obesity } & \multirow[t]{2}{*}{ At least one } \\
\hline & & & & High Risk & Diabetic & Overweight & Obese & \\
\hline \multicolumn{9}{|l|}{ Age } \\
\hline 18 to 29 & 45 (15.6) & $110(38.2)$ & $35(12.2)$ & $59(20.5)$ & $6(2.1)$ & $28(9.7)$ & $113(39.2)$ & $185(64.2)$ \\
\hline 30 to 39 & $47(22.1)$ & $100(46.9)$ & $45(21.1)$ & $79(37.1)$ & $11(5.2)$ & $39(18.3)$ & $111(52.1)$ & $181(85.0)$ \\
\hline 40 to 49 & $109(42.8)$ & $159(62.4)$ & $49(19.2)$ & $109(42.8)$ & $17(6.7)$ & 38 (14.9) & $164(64.3)$ & $232(91.0)$ \\
\hline 50 to 59 & $128(63.7)$ & $124(61.7)$ & $28(13.9)$ & $93(46.3)$ & $36(17.9)$ & $31(15.4)$ & $128(63.7)$ & $195(97.0)$ \\
\hline$>60$ & $102(73.4)$ & $71(51.1)$ & $22(15.8)$ & $76(54.7)$ & $16(11.5)$ & $22(15.8)$ & $84(60.4)$ & $133(95.7)$ \\
\hline prob. & $<0.0001$ & $<0.0001$ & $<0.0001$ & \multicolumn{2}{|c|}{$<0.0001$} & \multicolumn{2}{|c|}{$<0.0001$} & $<0.0001$ \\
\hline \multicolumn{9}{|l|}{ Education } \\
\hline None & $42(53.9)$ & $39(50.0)$ & $11(14.1)$ & $33(42.3)$ & $6(7.7)$ & $6(7.7)$ & $43(55.1)$ & $67(85.9)$ \\
\hline Primary & 109 (58.6) & $92(49.5)$ & $28(15.1)$ & $80(43.0)$ & $22(11.8)$ & $33(17.7)$ & $112(60.2)$ & $168(90.3)$ \\
\hline Secondary & $261(36.4)$ & $386(53.8)$ & $126(17.6)$ & $267(37.2)$ & $53(7.4)$ & 105 (14.6) & $389(54.2)$ & $610(85.0)$ \\
\hline Tertiary & $19(16.7)$ & $47(41.2)$ & $14(12.3)$ & $36(31.6)$ & $5(4.4)$ & $14(12.3)$ & $56(49.1)$ & $84(71.1)$ \\
\hline prob. & $<0.0001$ & $>0.05$ & $>0.1$ & \multicolumn{2}{|c|}{$<0.05$} & \multicolumn{2}{|c|}{$<0.05$} & $<0.0001$ \\
\hline \multicolumn{9}{|l|}{ Income } \\
\hline$<1,000$ & $97(50.5)$ & $96(50.0)$ & $33(17.2)$ & $77(40.1)$ & $12(6.3)$ & $26(13.5)$ & $95(49.5)$ & $169(88.0)$ \\
\hline$\geq 1,000$ & $334(36.9)$ & $468(51.8)$ & $146(16.2)$ & $339(37.5)$ & $74(8.2)$ & $132(14.6)$ & $505(55.9)$ & $757(83.7)$ \\
\hline prob. & $<0.001$ & $>0.1$ & $>0.1$ & \multicolumn{2}{|c|}{$>0.1$} & \multicolumn{2}{|c|}{$>0.1$} & $>0.1$ \\
\hline \multicolumn{9}{|l|}{ Occupation } \\
\hline Paid-employee & $137(29.6)$ & $238(51.4)$ & $98(21.2)$ & $171(36.9)$ & $27(5.8)$ & 77 (16.6) & $250(54.0)$ & $389(84.0)$ \\
\hline Self-employed & $63(45.7)$ & $82(59.4)$ & $39(28.3)$ & $60(43.5)$ & $18(13.0)$ & $15(10.9)$ & $84(60.9)$ & $127(92.0)$ \\
\hline Retiree & $30(71.4)$ & $19(45.2)$ & $11(26.2)$ & $23(54.8)$ & $4(9.5)$ & 7 (16.7) & $25(59.5)$ & $38(90.5)$ \\
\hline House maker & $113(47.7)$ & $136(57.4)$ & $3(1.3)$ & $92(38.8)$ & $21(8.9)$ & $34(14.4)$ & $143(60.3)$ & $208(87.8)$ \\
\hline Others & $88(40.7)$ & $89(41.2)$ & $28(13.0)$ & $70(32.4)$ & $16(17.4)$ & 25 (11.6) & $98(45.4)$ & $164(75.9)$ \\
\hline prob. & $<0.0001$ & $<0.01$ & $<0.0001$ & \multicolumn{2}{|c|}{$<0.01$} & \multicolumn{2}{|c|}{$<0.01$} & $<0.0001$ \\
\hline \multicolumn{9}{|l|}{ Marital status } \\
\hline Single & $61(22.0)$ & $100(36.1)$ & 35 (12.6) & $65(23.5)$ & $9(3.3)$ & $25(9.0)$ & $115(41.5)$ & $186(67.2)$ \\
\hline Married & $300(42.8)$ & $404(57.6)$ & $137(19.5)$ & $298(42.5)$ & $62(8.8)$ & $115(16.4)$ & $413(58.9)$ & $632(90.2)$ \\
\hline Divorced & $36(53.7)$ & $35(52.2)$ & $6(9.0)$ & $30(44.8)$ & $9(13.4)$ & $8(11.9)$ & $45(67.2)$ & $63(94.0)$ \\
\hline Widow/Widower & $34(66.7)$ & $25(49.0)$ & $1(2.0)$ & $23(45.1)$ & $6(11.8)$ & 10 (19.6) & $27(52.9)$ & $45(88.2)$ \\
\hline prob. & $<0.0001$ & $<0.0001$ & $<0.0001$ & \multicolumn{2}{|c|}{$<0.0001$} & \multicolumn{2}{|c|}{$<0.0001$} & $<0.0001$ \\
\hline Total & 431 (39.3) & $564(51.5)$ & $179(16.3)$ & $416(38.0)$ & $86(7.8)$ & $158(14.4)$ & $600(54.8)$ & $926(84.5)$ \\
\hline
\end{tabular}




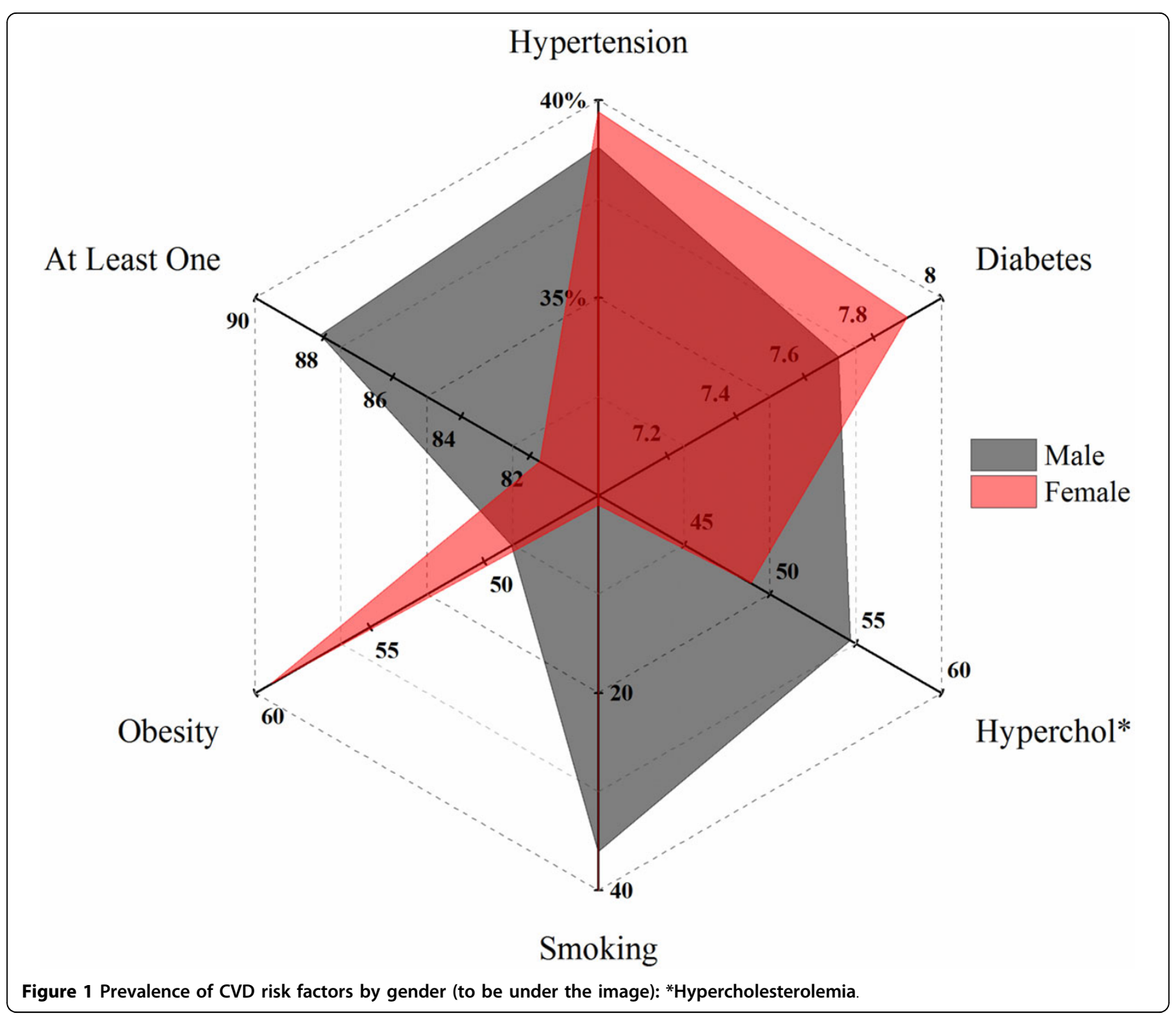

Figure 2 illustrates that all CVD risk factors were lowest among Indians except diabetes in which they had the highest prevalence (11.1\% comparing to 7.2 and 6.7 percent in Malays and Chinese respectively) (see Figure 2).

\section{Logistic regression analysis}

Crude and adjusted results of multivariate binary logistic regressions identified the significant determinants of the existence of at least one of the CVD risk factors in the low-income communities. The multivariate model showed that Indians were $41 \%$ less probable to have at least one of the CVD risk factors $(\mathrm{OR}=0.59 ; 95 \% \mathrm{CI}: 0.37-0.93)$ as compared to the Malay ethnic group. Occupational categories illustrated that the paid-employees were two times more likely to have more than one risk factor as compared to the reference group $(\mathrm{OR}=2.09 ; 95 \% \mathrm{CI}: 1.12-3.89)$ (see Table 3).
While a few contrasts were revealed, our study was generally in line with the literature. The prevalence of hypertension was increasing with age [15,33]. A previous study showed that in Malaysia, the prevalence of hypercholesterolemia was directly related to ageing, and this tallied with our findings as well [46]; however, our findings contradicted with a previous finding in which a greater proportion of females suffered from hypercholesterolemia[15]. Males smoked more than females in our study respondents. It is in line with previous studies, but the prevalence of smoking was even higher than the national average $[14,47]$. It was previously shown that Malays shared the highest prevalence of CVD risk factors except diabetes, in which Indians had the highest dominance $[10,48,49]$. Our study supported these findings that the low-income Indians were more diabetic, and the prevalence of diabetic adults was approximately 


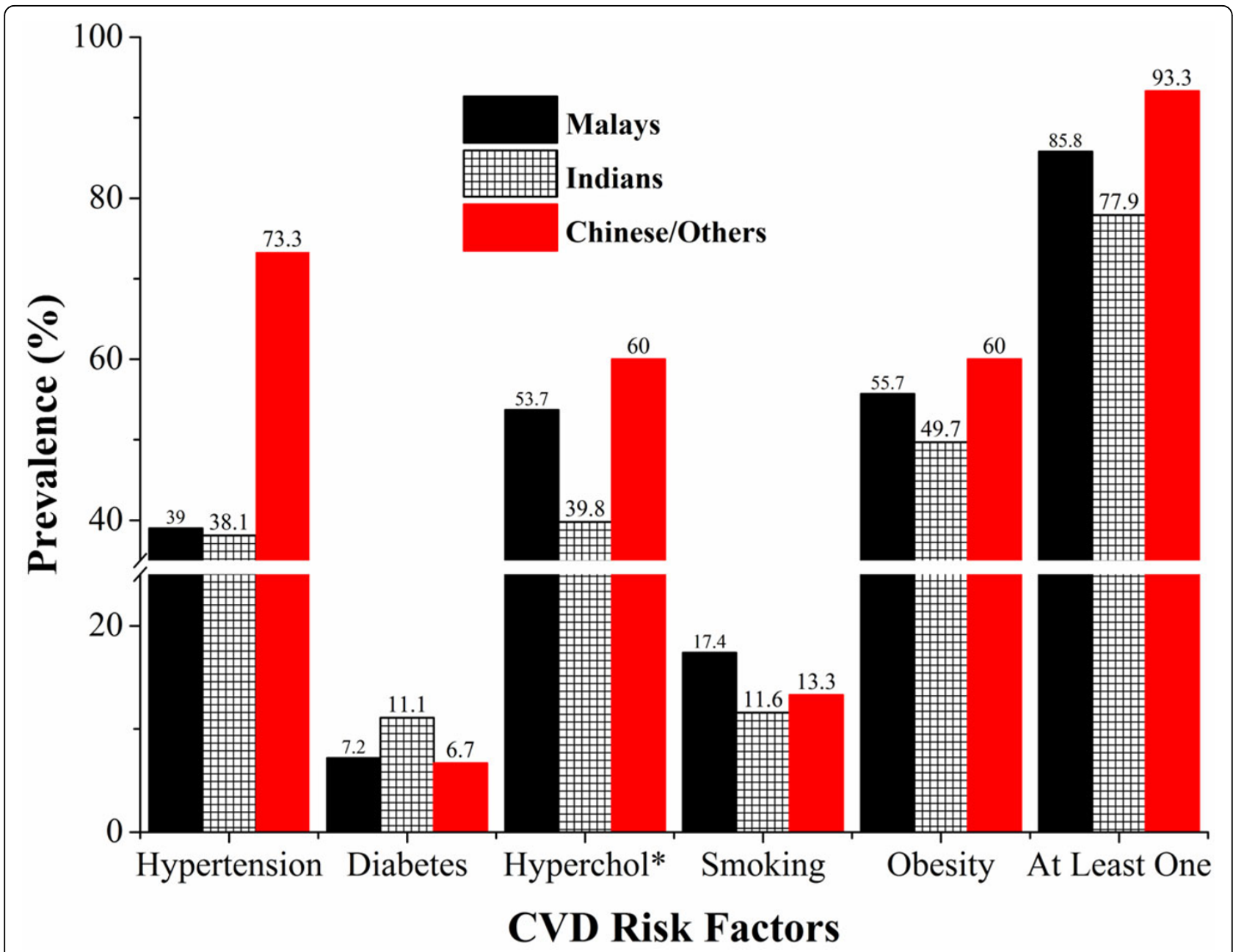

Figure 2 Ethnic differences in prevalence of CVD risk factors (to be under the image): *Hypercholesterolemia.

the national levels as reported formerly [14]. However, the results did not show significant difference in the prevalence of CVD risk factors among all ethnic groups except in hypercholesterolemia $(\mathrm{p}<0.01)$ and hypertension $(\mathrm{p}<$ $0.05)$ risk factors.

Furthermore, our study supported previous findings in which high-income adults were more obese [32,50,51]. It nevertheless contradicted with the overweight category in which lower educated respondents had higher prevalence of being overweight [32]. In addition, lower grades of education were related to higher prevalence of hypertension $[9,10,33]$. Besides, the poorer adults had higher prevalence of the presence of at least one of the CVD risk factors [52]. We additionally found that in the low-income urban communities, the self-employed adults had the highest prevalence of hypercholesterolemia, smoking, obesity, and at least one of the CVD risk factors, which may be due to stressful working environment. Considering marital status, we found it is related to all CVD risk factors including overweight/obesity [53] and smoking [43].

Results from the binary logistic regressions identified that age $[9,48]$ and gender $[9,10]$ were significant determinants of the existence of at least one of the CVD risk factors in the low-income community. Finally, the selfemployed and retired adults had the highest likelihood of having at least one of the CVD risk factors compared to the other groups. However, the results from multivariate logistic regressions indicated that compared to Malays, the Indians had the lowest likelihood of having at least one of the CVD risk factors[15], while the paidemployee category was the most significant category in occupational status.

\section{Conclusion}

The low-income and the poor communities in Malaysia had higher prevalence of CVD risk factors compared to the recent epidemiologic research $[14,15]$. Specifically, 
Table 3 Logistic regression results of the cumulative ${ }^{1}$ CVD risk factor

\begin{tabular}{|c|c|c|}
\hline & Adjusted & Crude \\
\hline & $\mathrm{OR}^{2}\left(\mathrm{Cl}^{3}\right)$ & $\mathrm{OR}(\mathrm{Cl})$ \\
\hline Age & $1.08^{* * *}(1.05-1.10)$ & $1.08^{* * *}(1.06-1.10)$ \\
\hline \multicolumn{3}{|l|}{ Gender } \\
\hline Female & $0.49 * *(0.32-0.75)$ & $0.60 * *(0.42-0.84)$ \\
\hline Male & Reference & Reference \\
\hline \multicolumn{3}{|l|}{ Ethnicity } \\
\hline Indian & $0.59 *(0.37-0.93)$ & $0.58^{* *}(0.39-0.87)$ \\
\hline Chinese/Others & $1.21(0.13-10.71)$ & $2.34(0.30-17.96)$ \\
\hline Malay & Reference & Reference \\
\hline \multicolumn{3}{|l|}{ Education } \\
\hline Primary & $1.18(0.44-3.18)$ & $1.53(0.68-3.41)$ \\
\hline Secondary & $1.90(0.78-4.63)$ & $0.92(0.47-1.81)$ \\
\hline Tertiary & $1.92(0.72-5.11)$ & $0.40 *(0.18-0.85)$ \\
\hline None & Reference & Reference \\
\hline \multicolumn{3}{|l|}{ Income } \\
\hline$\geq 1,000 R M$ & $0.81(0.47-1.39)$ & $0.70(0.43-1.12)$ \\
\hline$<1,000 R M$ & Reference & Reference \\
\hline \multicolumn{3}{|l|}{ Occupation } \\
\hline Retiree & $1.99(0.89-4.45)$ & $9.89 * * *(4.97-19.66)$ \\
\hline House maker & $2.13(0.94-4.82)$ & $8.04^{* * *}(4.37-14.78)$ \\
\hline Paid-employee & $2.10 *(1.13-3.91)$ & $5.89 * * *(3.46-10.02)$ \\
\hline Self-employed & $2.12(0.86-5.21)$ & $12.94^{* * *}(5.96-28.08)$ \\
\hline Others & Reference & Reference \\
\hline \multicolumn{3}{|l|}{ Marital Status } \\
\hline Single & $1.93(0.60-6.16)$ & $0.27^{* *}(0.11-0.66)$ \\
\hline Married & $2.50(0.89-7.05)$ & $1.22(0.50-2.96)$ \\
\hline Divorced & $3.09(0.77-12.45)$ & $2.09(0.56-7.87)$ \\
\hline Widow/Widower & Reference & Reference \\
\hline
\end{tabular}

Note: 1. Existence of at least one CVD risk factor 2. Odds-Ratios 3. Confidence Interval (95\%)

*. $\mathrm{P}<0.05^{* *} . \mathrm{P}<0.01 * * * . \mathrm{P}<0.0001$

Malays, compared to Indians; and paid-employees compared to the other occupation categories, experienced the highest prevalence of CVD risk factors. This high prevalence may be as a consequence of delays and/or not seeking appropriate treatments, unhealthy dietary habits and physical inactivity of these groups [15]. In addition, the occupational stress may be the other cause for the high prevalence of CVD risk factors (specifically smoking) among the paid-employees in the low-income communities of Malaysia [54]. Therefore, ethnic backgrounds and occupational status of the low-income communities must be considered for the prospective public health policies and interventions.

Our research had a few limitations which should be prevented in future studies. First, defining diabetes would be more reliable if the fasting blood samples were collected. Second, alcohol consumption data in Malaysia is quite limited due to social and religious aspects. Besides, since the number of Chinese, Indians, and other ethnic groups were too low, we could not present rough estimates of these ethnic groups specifically. Finally, our study was not a representative of the national low-income Malaysians but it broadly illustrated the low-income urban population of Malaysia.

Nonetheless, the CVD risk factors in the low-income and the poor Malaysians in the urban community were quite obvious in this study. Hence, a thorough attention is needed in future policies to reduce CVD risk factors among the low-income communities.

\section{List of abbreviations}

CVD: Cardiovascular Disease; SES: Socioeconomic Status; NCD: NonCommunicable Disease; PPR: ProjekPerumahan Rakyat (Community Housing Project); RBS: Random Blood Sugar; BMI: Body Mass Index; MYR: Malaysian Ringgit; PLI: Poverty Line Income; OR: Odds-Ratio; Cl: Confidence Interval.

\section{Competing interests}

The authors declare that they have no competing interests.

\section{Authors' contributions}

STT: was responsible for the design of the research, collection of data, analysis and helps write-up. AM conducted the analyses and write-up of manuscript. AMH helped with the design, data collection and write-up. MHF helped with the data collection and write-up. TN conducted the data collection and helped with the write-up. MBA helped with the design and final write-up of this paper.

\section{Acknowledgements}

This "Participatory Action Research through Negotiation and Empowerment of the Residents (PARTNER)"study was funded by Health and Translational Medicine Cluster Flagship Fund No. FL009-2011 (Ethic approval number: MEC Ref No. 890.161).

This article has been published as part of BMC Public Health Volume 14 Supplement 3, 2014: Proceedings of the International Research Symposium on Population Health 2013. The full contents of the supplement are available online at http://www.biomedcentral.com/bmcpublichealth/ supplements/14/S3. Publication charges for this supplement were funded by the University of Malaya.

\section{Authors' details}

${ }^{1}$ Department of Development Studies, Faculty of Economics and Administration, University of Malaya, 50603, Kuala Lumpur, Malaysia. ${ }^{2}$ Centre for Population Health (CePH), Department of Social and Preventive Medicine, Faculty of Medicine, University of Malaya, 50603, Kuala Lumpur, Malaysia. ${ }^{3}$ Julius Centre University of Malaya (JCUM), Department of Social and Preventive Medicine, Faculty of Medicine, University of Malaya, 50603, Kuala Lumpur, Malaysia.

\section{Published: 24 November 2014}

\section{References}

1. Yusuf S, Reddy S, Ounpuu S, Anand S: Global burden of cardiovascular diseases: part I: general considerations, the epidemiologic transition, risk factors, and impact of urbanization. Circulation 2001, 104:2746-2753.

2. Yusuf S, Reddy S, Ounpuu S, Anand S: Global burden of cardiovascular diseases: Part II: variations in cardiovascular disease by specific ethnic groups and geographic regions and prevention strategies. Circulation 2001, 104:2855-2864.

3. Yasin S, Chan CK, Reidpath DD, Allotey P: Contextualizing chronicity: a perspective from Malaysia. Global Health 2012, 8:4.

4. Cooper R, Cutler J, Desvigne-Nickens P, Fortmann SP, Friedman L, Havlik R, Hogelin G, Marler J, McGovern P, Morosco G, et al: Trends and disparities in coronary heart disease, stroke, and other cardiovascular diseases in the United States: findings of the national conference on cardiovascular disease prevention. Circulation 2000, 102:3137-3147. 
5. Hamer M, Chida Y: Active commuting and cardiovascular risk: a metaanalytic review. Preventive medicine 2008, 46:9-13.

6. Callow AD: Cardiovascular disease 2005-the global picture. Vascular pharmacology 2006, 45:302-307.

7. How we classify countries. [http://data.worldbank.org/about/countryclassifications]

8. Population Distribution And Basic Demographic Characteristic Report 2010. [http://www.statistics.gov.my/portal/index.php? option=com content\&id $=1215 \&$ ltemid $=89 \&$ lang $=e n]$.

9. Rampal S, Rampal L, Rahmat R, Zain AM, Yap YG, Mohamed M, Taha M: Variation in the prevalence, awareness, and control of diabetes in a multiethnic population: a nationwide population study in Malaysia. AsiaPacific journal of public health / Asia-Pacific Academic Consortium for Public Health 2010, 22:194-202.

10. Amal NM, Paramesarvathy R, Tee GH, Gurpreet K, Karuthan C: Prevalence of Chronic Illness and Health Seeking Behaviour in Malaysian Population: Results from the Third National Health Morbidity Survey (NHMS III) 2006. Med J Malaysia 2011, 66:36-41.

11. Stuckler D: Population causes and consequences of leading chronic diseases: a comparative analysis of prevailing explanations. Milbank $O$ 2008, 86:273-326.

12. Ministry of Health Malaysia: The Second National Health and Morbidity Survey (NHMS II). City: Institute of Public Health;Book The Second National Health and Morbidity Survey (NHMS II) 1996:, (Editor ed.^eds.).

13. Ministry of Health Malaysia: The Third National Health and Morbidity Survey (NHMS III). City: Institute of Public Health;Book The Third National Health and Morbidity Survey (NHMS III), (Editor ed.^eds.)

14. Ministry of Health Malaysia: The Fourth National Health and Morbidity Survey (NHMS IV). City: Institute of Public Health;Book The Fourth National Health and Morbidity Survey (NHMS IV) 2011:; (Editor ed.^eds.)..

15. Rasiah R, Yusoff K, Mohammadreza A, Manikam R, Tumin M, Chandrasekaran SK, Khademi S, Bakar NA: Cardiovascular disease risk factors and socioeconomic variables in a nation undergoing epidemiologic transition. BMC Public Health 2013, 13:886.

16. Codes \& Classifications. [http://www.statistics.gov.my/portal/index.php? option=com content\&view=article\&id=1492\&ltemid=99\&lang=en] .

17. Abegunde DO, Mathers CD, Adam T, Ortegon M, Strong K: The burden and costs of chronic diseases in low-income and middle-income countries. Lancet 2007, 370:1929-1938.

18. Adler NE, Ostrove JM: Socioeconomic status and health: What we know and what we don't. Ann Ny Acad Sci 1999, 896:3-15.

19. Blane D, Hart CL, Smith GD, Gillis CR, Hole DJ, Hawthorne VM: Association of cardiovascular disease risk factors with socioeconomic position during childhood and during adulthood. BMJ 1996, 313:1434-1438.

20. Scholes S, Bajekal M, Love H, Hawkins N, Raine R, O'Flaherty M, Capewell S: Persistent socioeconomic inequalities in cardiovascular risk factors in England over 1994-2008: a time-trend analysis of repeated crosssectional data. BMC Public Health 2012, 12:129.

21. Kim D, Kawachi I, Hoorn SV, Ezzati M: Is inequality at the heart of it? Cross-country associations of income inequality with cardiovascular diseases and risk factors. Soc Sci Med 2008, 66:1719-1732.

22. Kivimaki M, Gimeno D, Ferrie JE, Batty GD, Oksanen T, Jokela M, Virtanen M, Salo P, Akbaraly TN, Elovainio M, et al: Socioeconomic position, psychosocial work environment and cerebrovascular disease among women: the Finnish public sector study. Int J Epidemiol 2009, 38:1265-1271.

23. Stelmach W, Kaczmarczyk-Chalas K, Bielecki W, Stelmach I, Drygas W: How income and education contribute to risk factors for cardiovascular disease in the elderly in a former Communist country. Public Health 2004, 118:439-449

24. Barbeau EM, Krieger N, Soobader MJ: Working class matters: socioeconomic disadvantage, race/ethnicity, gender, and smoking in NHIS 2000. American journal of public health 2004, 94:269-278.

25. Torun B, Stein AD, Schroeder D, Grajeda R, Conlisk A, Rodriguez M, Mendez $\mathrm{H}$, Martorell R: Rural-to-urban migration and cardiovascular disease risk factors in young Guatemalan adults. Int J Epidemiol 2002, 31:218-226.

26. Teo K, Chow CK, Vaz M, Rangarajan S, Yusuf S, Group PI-W: The Prospective Urban Rural Epidemiology (PURE) study: examining the impact of societal influences on chronic noncommunicable diseases in low-, middle-, and high-income countries. American heart journal 2009, 158:1-7 e1.
27. Choinière R, Lafontaine $P$, Edwards AC: Distribution of cardiovascular disease risk factors by socioeconomic status among Canadian adults. Canadian Medical Association Journal 2000, 162:S13-S24.

28. Gaziano TA, Opie LH, Weinstein MC: Cardiovascular disease prevention with a multidrug regimen in the developing world: a cost-effectiveness analysis. Lancet 2006, 368:679-686.

29. Lim SS, Gaziano TA, Gakidou E, Reddy KS, Farzadfar F, Lozano R, Rodgers A: Prevention of cardiovascular disease in high-risk individuals in lowincome and middle-income countries: health effects and costs. Lancet 2007, 370:2054-2062.

30. Tai ES, Poulton R, Thumboo J, Sy R, Castillo-Carandang N, Sritara P, Adam JMF, Sim KH, Fong A, Wee HL, Woodward M: An update on cardiovascular disease epidemiology in South East Asia. Rationale and design of the LIFE course study in CARdiovascular disease Epidemiology (LIFECARE). CVD Prevention and Control 2009, 4:93-102.

31. Tully MA, Cupples ME, Chan WS, McGlade K, Young IS: Brisk walking, fitness, and cardiovascular risk: a randomized controlled trial in primary care. Preventive medicine 2005, 41:622-628.

32. Azmi MY, Junidah R, Siti Mariam A, Safiah MY, Fatimah S, Norimah AK, Poh BK, Kandiah M, Zalilah MS, Wan Abdul Manan W, et al: Body Mass Index (BMI) of Adults: Findings of the Malaysian Adult Nutrition Survey (MANS). Malays J Nutr 2009, 15:97-119.

33. Rampal L, Rampal S, Azhar MZ, Rahman AR: Prevalence, awareness, treatment and control of hypertension in Malaysia: a national study of 16,440 subjects. Public Health 2008, 122:11-18.

34. Tan AK, Yen ST, Nayga RM: Role of Education in Cigarette Smoking: An Analysis of Malaysian Household Survey Data. Asian Economic Journal 2009, 23:1-17.

35. Ismail IS, Nazaimoon WM, Mohamad WB, Letchuman R, Singaraveloo M, Pendek R, Faridah I, Rasat R, Sheriff IH, Khalid BA: Sociodemographic determinants of glycaemic control in young diabetic patients in peninsular Malaysia. Diabetes Res Clin Pract 2000, 47:57-69.

36. Klein BE, Klein R, Lee KE: Cardiovascular disease, selected cardiovascular disease risk factors, and age-related cataracts: the Beaver Dam Eye Study. Am J Ophthalmol 1997, 123:338-346.

37. Letchuman GR, Wan Nazaimoon WM, Wan Mohamad WB, Chandran LR Tee GH, Jamaiyah H, Isa MR, Zanariah H, Fatanah I, Ahmad Faudzi Y: Prevalence of diabetes in the Malaysian National Health Morbidity Survey III 2006. Med J Malaysia 2010, 65:180-186.

38. WHO Expert Consultation: Appropriate body-mass index for Asian populations and its implications for policy and intervention strategies. Lancet 2004, 363:157.

39. Ko GT, Chan JC, Cockram CS, Woo J: Prediction of hypertension, diabetes, dyslipidaemia or albuminuria using simple anthropometric indexes in Hong Kong Chinese. International journal of obesity and related metabolic disorders : journal of the International Association for the Study of Obesity 1999, 23:1136-1142

40. Pan WH, Flegal KM, Chang HY, Yeh WT, Yeh CJ, Lee WC: Body mass index and obesity-related metabolic disorders in Taiwanese and US whites and blacks: implications for definitions of overweight and obesity for Asians. Am J Clin Nutr 2004, 79:31-39.

41. Shiwaku K, Anuurad E, Enkhmaa B, Kitajima K, Yamane Y: Appropriate BMI for Asian populations. The Lancet 2004, 363:1077.

42. Wildman RP, Gu DF, Reynolds K, Duan XF, He J: Appropriate body mass index and waist circumference cutoffs for categorization of overweight and central adiposity among Chinese adults. American Journal of Clinical Nutrition 2004, 80:1129-1136.

43. Huxley RR, Woodward M: Cigarette smoking as a risk factor for coronary heart disease in women compared with men: a systematic review and meta-analysis of prospective cohort studies. Lancet 2011, 378:1297-1305.

44. Household Income \& Poverty. [http://www.epu.gov.my/en/householdincome-poverty;jsessionid=9DDF39109601FE21030AD5461AE49660].

45. von Elm E, Altman DG, Egger M, Pocock SJ, Gotzsche PC, Vandenbroucke JP, Initiative S: The Strengthening the Reporting of Observational Studies in Epidemiology (STROBE) statement: guidelines for reporting observational studies. Preventive medicine 2007, 45:247-251.

46. Castanho VS, Oliveira LS, Pinheiro HP, Oliveira HC, de Faria EC: Sex differences in risk factors for coronary heart disease: a study in a Brazilian population. BMC Public Health 2001, 1:3. 
47. Al-Sadat N, Misau AY, Zarihah Z, Maznah D, Tin Tin S: Adolescent tobacco use and health in Southeast Asia. Asia Pacific Journal of Public Health 2010 22:175S-180S

48. Amplavanar N, Gurpreet K, Salmiah M, Odhayakumar N: Prevalence of cardiovascular disease risk factors among attendees of the Batu 9, Cheras Health Centre, Selangor, Malaysia. Med J Malaysia 2010, 65:173.

49. Hong CY, Chia KS, Hughes K, Ling SL: Ethnic differences among Chinese, Malay and Indian patients with type 2 diabetes mellitus in Singapore. Singapore Medical Journal 2004, 45:154-160.

50. Yunus AM, Sherina M, Nor Afiah M, Rampal L, Tiew K: Prevalence of cardiovascular risk factors in a rural community in mukim dengkil, selangor. Malays J Nutr 2004, 10:5-11.

51. Ismail MN, Chee SS, Nawawi H, Yusoff K, Lim TO, James WP: Obesity in Malaysia. Obesity reviews : an official journal of the International Association for the Study of Obesity 2002, 3:203-208.

52. Ezeamama AE, Viali S, Tuitele J, McGarvey ST: The influence of socioeconomic factors on cardiovascular disease risk factors in the context of economic development in the Samoan archipelago. Soc Sci Med 2006, 63:2533-2545.

53. Tan AK, Yen ST, Feisul Ml: Determinants of body weight status in Malaysia: an ethnic comparison. Int J Public Health 2012, 57:279-288.

54. Makhbul ZM, Idrus D: Work Stress Issues in Malaysia. Malaysia Labour Review 2009, 3:13-26.

doi:10.1186/1471-2458-14-S3-S3

Cite this article as: Amiri et al:: Prevalence and determinants of cardiovascular disease risk factors among the residents of urban community housing projects in Malaysia. BMC Public Health 2014 14(Suppl 3):S3.

\section{Submit your next manuscript to BioMed Central and take full advantage of:}

- Convenient online submission

- Thorough peer review

- No space constraints or color figure charges

- Immediate publication on acceptance

- Inclusion in PubMed, CAS, Scopus and Google Scholar

- Research which is freely available for redistribution

Submit your manuscript at www.biomedcentral.com/submit 